\title{
APLICAÇÃO ESTRUTURAL DO BAMBU - TESOURAS DE DUAS ÁGUAS: ANÁLISE TEÓRICA-EXPERIMENTAL
}

\author{
BAMBOO STRUCTURAL APPLICATION - DOUBLE PITCHED \\ TRUSS: THEORETICAL-EXPERIMENTAL ANALYSIS
}

\author{
GILBERTO CARBONARI, Dr. | UEL \\ GUSTAVO PRONI|UEL \\ VITÓRIA MARIA GONÇALVES |UEL
}

\begin{abstract}
RESUMO
O bambu é uma excelente alternativa sustentável, de elevada resistência, com baixo peso específico e renovável. Graças a um tratamento natural eficiente descoberto recentemente, utilizando Tanino, a durabilidade conferida permite a sua utilização em várias aplicações na construção civil. O objetivo do trabalho foi obter um método para execução de tesouras mais eficientes estruturalmente e verificar a sua viabilidade prática em coberturas de edificações. Para isto, foram executadas 6 tesouras de bambu, da espécie Dendrocalamus giganteus, reforçadas com graute e abraçadeiras metálicas. As tesouras foram posicionadas em um pórtico em que uma carga concentrada foi aplicada no ponto superior da tesoura até a ruptura, gerando dados de deslocamentos e cargas últimas. Desta forma, analisou-se o comportamento de cada tesoura quando submetida à esforços. Os resultados comprovaram que os reforços, além da utilização de barras roscadas nas uniões das barras das tesouras, agregam um significativo acréscimo de resistência mecânica para a referida estrutura. Além disso, os valores obtidos das cargas e deslocamentos nos ensaios realizados permitiram concluir que as tesouras podem ser usadas com segurança em coberturas de edificações, pois atendem aos critérios do Estado Limite de Serviço (E.L.S.) e do Estado Limite Último (E.L.U.).
\end{abstract}

PALAVRAS CHAVE: Tesouras de bambu; Eficiência estrutural; Aplicação estrutural; Análise teórica e experimental.

\begin{abstract}
Bamboo is an excellent sustainable alternative with high resistance, low specific weight and renewable. By reason of an efficient natural treatment utilizing Tannin discovered recently, the durability conferred allows its use in several applications at civil construction. The aim of this work was to obtain a method more structurally efficient to the execution of howe trusses and to verify their practical viability at buildings' roofs. For this, six howe trusses of Dendrocalamus giganteus species reinforced with groute and metal clamps were executed. The howe trusses were placed in a gantry, where a concentrated load was applied at the howe truss' upper point until the rupture, generating data of displacements and ultimate loads. In this way, the behavior of each howe truss when submitted to the efforts was analyzed. The results showed that the reinforcements, besides the use of threaded bars in the joints between elements of the howe trusses, contribute with a significant increase of mechanical resistance to the structure. Furthermore, the results of the loads and displacements obtained in the tests allow to conclude that howe trusses can be safely used at the buildings' roofs, because meets with the criteria of the Ultimate Limit State and Service Limit State.
\end{abstract}

KEY WORDS: Howe trusses; Structural efficiency; Structural application; Theoretical and experimental analysis. 


\section{INTRODUÇÃO}

A construção civil representa aproximadamente $8 \%$ do PIB brasileiro, e gera cerca de 13 milhões de empregos formais, informais e indiretos, tendo notável relevância na economia do país. Porém, é um dos setores que mais poluem o meio ambiente, sendo responsável por cerca de $40 \%$ a $75 \%$ da matéria-prima extraída no planeta, além de ser a atividade produtiva que mais gera resíduos.

O desenvolvimento sustentável é um desafio muito grande, que deve se integrar com o desenvolvimento econômico e social. Dessa forma, é extremamente necessário que alternativas sustentáveis para a construção se sobressaiam, e é nesse contexto que o bambu se torna interessante para a construção civil.

O bambu também tem grande potencial em habitações de interesse social. O Brasil tem um déficit de 6,2 milhões de moradias, e a maior parte deste déficit é de habitações de baixo padrão, o que abre espaço para a utilização do bambu.

O uso do bambu garante tesouras leves e resistentes. "O bambu é um material com grande resistência. A razão entre o peso do bambu e a força que ele suporta é superior à do aço." (CARBONARI et al 2017; VASCONCELLOS, 2004).

Nos últimos 9 anos, o grupo de pesquisa Bambu-UEL cadastrado no CNPq, vem realizando pesquisas com bambu (BARBOSA, 2017; CARBONARI, 2013; CARBONARI et al., 2016; CARBONARI et al., 2017; GONÇALVES, 2018, PRONI, 2018), tanto na obtenção das propriedades mecânicas e estruturais, como também da sua durabilidade frente ao ataque de insetos, graças ao tratamento com tanino, através do Método de Boucherie modificado, conforme solicitação de patente depositada no IMPI (CARBONARI, 2013).

O tratamento com tanino teve sua eficiência comprovada recentemente e como uma das principais preocupações com o uso do bambu está relacionada com a sua durabilidade, especialmente relacionada com o ataque de insetos xilófagos (fungos e carunchos), este tratamento se torna extremamente importante.

Neste trabalho, apenas a espécie Dendrocalamus giganteus foi analisada, devido a suas grandes dimensões de diâmetro externo e espessura, que conferem maior resistência mecânica se comparadas a outras espécies.

$\mathrm{O}$ trabalho tem como objetivo determinar o método para a execução das tesouras com maior eficiência estrutural possível, comparando duas técnicas de reforço nos apoios das tesouras: as seis tesouras em bambu executadas possuem seus apoios preenchidos com graute, sendo três confinados por fitas metálicas furadas, e outras três com abraçadeiras de aço.
Além disso, tem o objetivo de avaliar se tesouras de bambu são viáveis estruturalmente para execução em coberturas de edificações, comparando com os resultados experimentais obtidos nos ensaios.

\section{REVISÃO BIBLIOGRÁFICA}

\subsection{Aspectos botânicos e anatomia}

O bambu é pertencente a subfamília Bambusoideae da família Poaceae, também conhecida como a família das gramíneas, que é dividida em dois grandes grupos: os herbáceos (Olyrae) e os lenhosos (Bambuseae). O habitat natural das espécies de bambu é, principalmente, em zonas tropicais e temperadas.

As duas partes constituintes mais importantes do bambu são o rizoma e o colmo, sendo que o rizoma tem a função de propagação da planta, que é feita por ramificações e de forma assexuada. Além disso, o rizoma tem função de armazenagem de nutrientes. $O$ colmo é a parte útil do bambu, propriamente dita, utilizado na construção civil. Sua geometria é circular oca, sendo composta por nó, entrenó, cavidade e diafragma.

\subsection{Tratamento do bambu}

O bambu tem a necessidade de tratamento pois é um material natural e possui o amido, o que ocasiona sua exposição ao ataque de insetos xilófagos (fungos e carunchos).

Existem alguns tipos de tratamento do bambu, como por exemplo: o tratamento químico, por imersão em água, através de fervura, entre outros.

Desde 2013, existe um tratamento natural, que utiliza tanino para aumentar a vida útil dos colmos de bambu. $\mathrm{O}$ tanino tem propriedades ácidas e adstringentes, que "neutralizam" o amido presente nas células parênquimas do bambu, acabando com o atrativo para os insetos xilófagos (CARBONARI, 2013).

\subsection{Propriedades físicas e mecânicas}

As propriedades físicas e mecânicas do bambu estão diretamente ligadas com sua estrutura anatômica.

As principais propriedades físicas do bambu são:

a) Idade do colmo: é um fator importante para se determinar a resistência do bambu. $\mathrm{O}$ ideal para o monitoramento da idade do bambu é etiqueta-lo logo quando brota do solo, porém se não for possível, pode-se estimar a idade através da observação de presença de fungos e coloração da superfície.

b) Densidade: varia de $700 \mathrm{~kg} / \mathrm{m}^{3}$ e $800 \mathrm{~kg} / \mathrm{m}^{3}$. Janssen (2000) comparou os fatores resistência e rigidez em relação a densidade de materiais convencionais na 
construção civil com o bambu, sendo que o bambu só "perderia" para o aço em relação a resistência, como pode ser visto na figura 1.

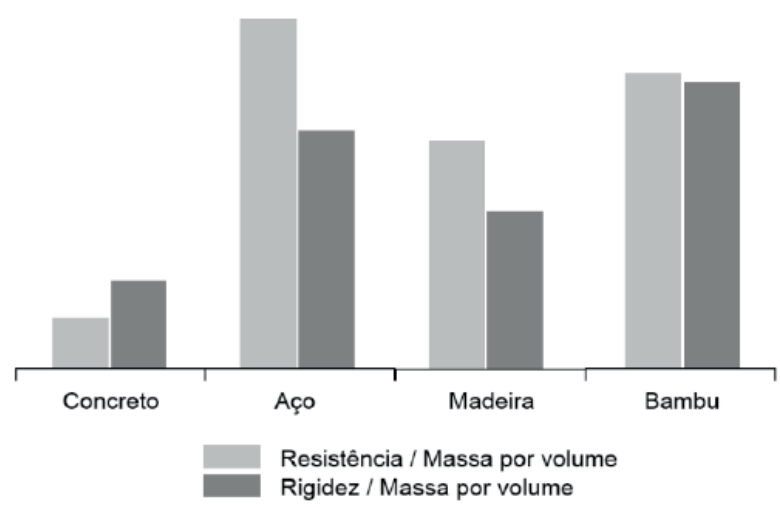

Figura 1-Comparação da resistência e rigidezem relação à densidade, do bambu com outros materiais. Fonte: JANSSEN (2000) apud SÁNCHEZ QUINTERO, p. 11.

c) Teor de umidade: varia com a idade, a estação do corte e espécie. Quanto mais novo o bambu, maior seu teor de umidade, sendo que até os três anos de idade, quando são considerados verdes, o teor é muito elevado, afetando a resistência do colmo. Após o corte, o bambu tende a perder umidade, aumentando o seu desempenho estrutural, sendo que a secagem do mesmo pode demorar de um a quatro meses dependendo das condições de armazenamento dos colmos.

Em relação às propriedades mecânicas, o conjunto de fatores do bambu, o torna resistente e flexível, sendo chamado de "aço vegetal". O bambu é um material anisotrópico, ou seja, possui características mecânicas diferentes nas três direções: longitudinal, tangencial e radial.

Para a espécie Dendrocalamus giganteus, os valores médios, segundo Carbonari (2015), são:

a) Compressão paralela as fibras:48,27 MPa e 46,32 MPa para corpos de prova com e sem nó respectivamente.

b) Tração paralela as fibras: $52 \mathrm{MPa}$ (com nó) e $133 \mathrm{MPa}$ (sem nó) no ensaio com fibras internas e $186 \mathrm{MPa}$ (com nó) e 203 MPa (sem nó) no ensaio com fibras externas.

c) Flexão: 58,5 MPa.

d) Módulo de elasticidade longitudinal: 21,90 GPa para colmos com nó, e 21,80 GPa para colmos sem nó.

A propriedade mecânica mais frágil do bambu é o cisalhamento. Ghavami e Marinho (2001), obtiveram valores médios de 3,56 MPa e 3,37 MPa para corpos de prova com e sem nó, respectivamente.

\subsection{Ligações das peças em bambu}

As ligações entre as peças que formam uma estrutura são fundamentais para a sua integridade, necessitando de uma perfeita adequação dos materiais que nela serão utilizados. Por causa da forma do bambu não perfeitamente circular, cônica, oca, com diversas dimensões em seu comprimento, diâmetro e espessura de paredes, as ligações são uma das maiores dificuldades em construções com bambu. (PADOVAN, 2010, p. 102).

Em relação aos cortes no bambu para a realização de encaixes, tem-se as seguintes formas de esculpir as extremidades, apresentadas na figura 2.
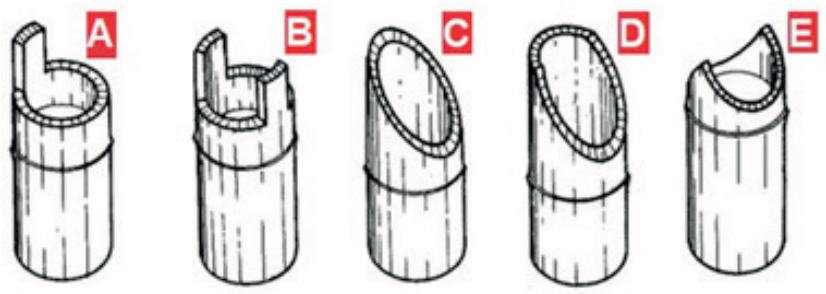

Figura 2 - Extremidades das varas de bambu Fonte: LÓPEZ, 1981, p. 24.

Um dos cuidados que devem ser tomados na execução das ligações, segundo López (1981), é a extremidade de uma vara de bambu possuir um diafragma, caso contrário, estará suscetível a sofrer achatamento sob a ação de uma carga vertical, conforme figura 3.

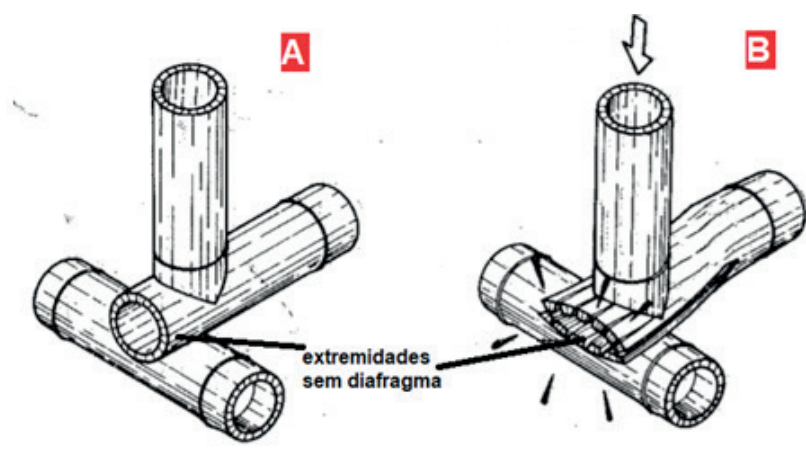

Figura 3 - Esmagamento do colmo na extremidade Fonte: LÓPEZ, 1981, p. 22.

Em relação a união das peças de bambu, esta pode ser realizada de diversas formas, nas figuras 4 e 5 estão expostas duas destas formas.

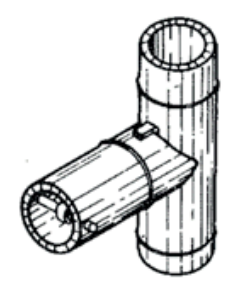

A

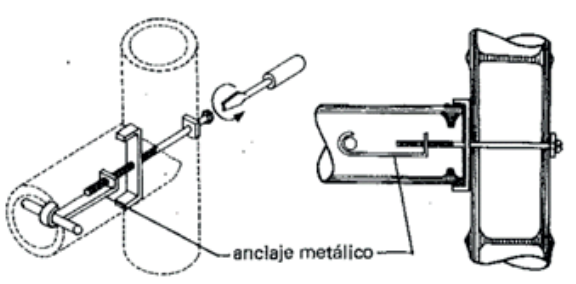

C
Figura 4 - União através de gancho metálico Fonte: LÓPEZ, 1981, p. 25. 


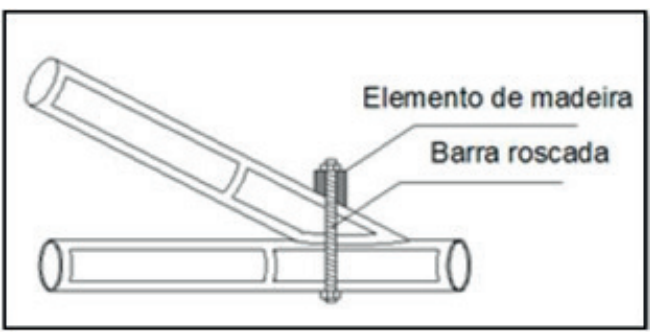

Figura 5 - União entre peças horizontais e diagonais Fonte: BARBOSA, 2017, p. 24.

Acerca de reforços nas ligações de bambu, Barbosa (2017) propôs a concretagem dos apoios de uma treliça, sendo que o concreto foi inserido através da cavidade do bambu e estancado com fitas e sacos plásticos, como apresenta a figura 6 .

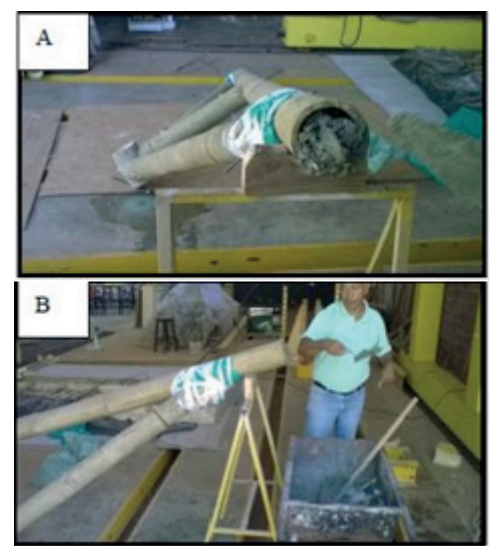

Figura 6 - Inserção de concreto no apoio Fonte: BARBOSA, 2017, p. 54

Padovan (2010) também cita uma conexão reforçada com argamassa. A figura 7 apresenta a forma de injeção desta argamassa.
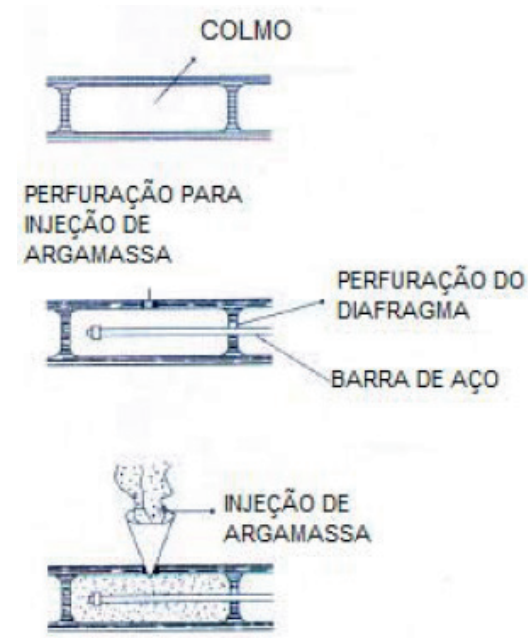

Figura 7 - Forma de injeção de argamassa no colmo de bambu Fonte: RWTH Aachen (2009, apud PADOVAN, 2010, p. 142).
Outro tipo de reforço são as abraçadeiras metálicas, que são utilizadas para dar aperto ao bambu e evitar que fendas se abram no colmo ou para reforçar fendas abertas. Barbosa (2017) também utilizou abraçadeiras metálicas nos apoios de uma tesoura, como mostra a figura 8, já a figura 9, mostra abraçadeiras reforçando a estrutura de uma cobertura de bambu.

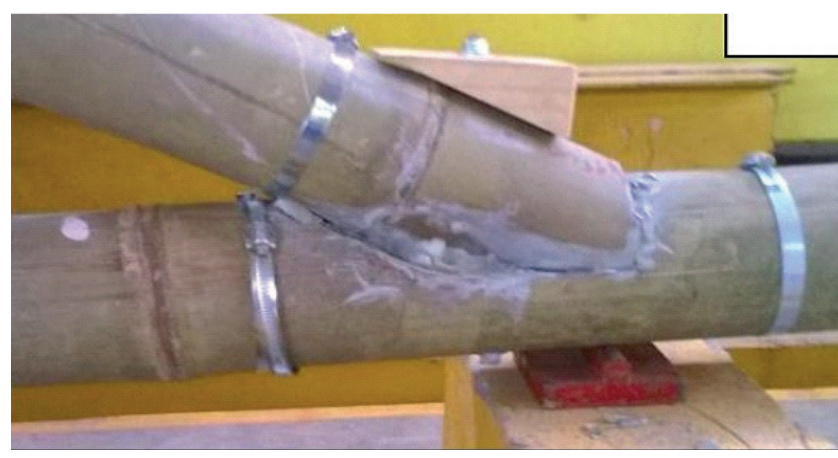

Figura 8 - Reforço de ligação com abraçadeira metálica Fonte: BARBOSA, 2017, p. 60.

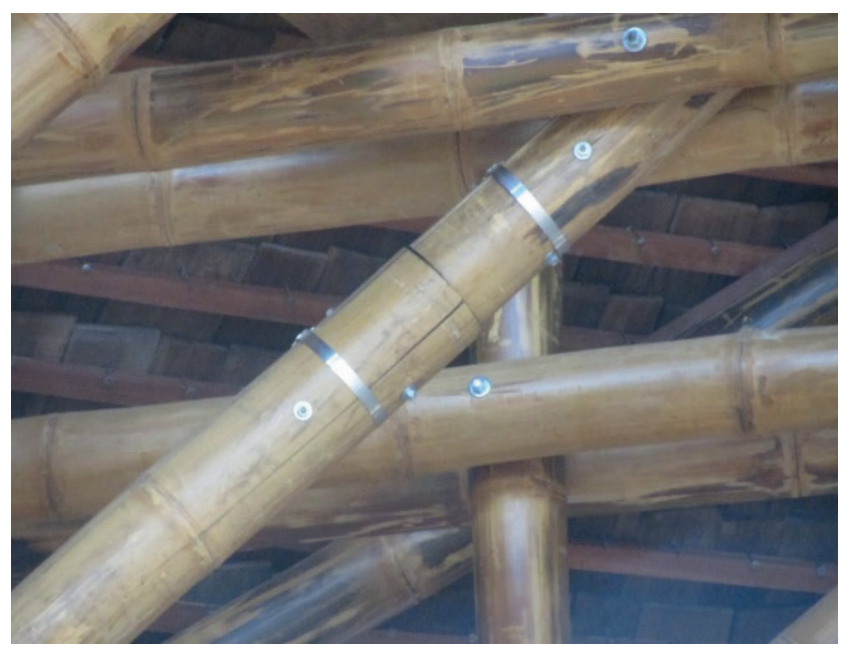

Figura 9 - Abraçadeira metálica reforçando peça de bambu na chácara do sindicato dos professores (DF)

Fonte: Autores.

\section{MATERIAIS E MÉTODOS}

Neste item se destacam os métodos para o cumprimento dos objetivos do trabalho, tendo uma abordagem sobre a montagem e configuração das tesouras, o ensaio experimental, e a verificação de uma aplicação prática da tesoura.

Para permitir conclusões estatisticamente representativas, foram ensaiadas seis tesouras em bambu, utilizando a técnica de ligação entre as peças por barras roscadas

Os cortes das barras de bambu foram efetuados no bambuzal da Universidade Estadual de Londrina. O critério de escolha foi coletar barras com idade entre $3 \mathrm{e}$ 
6 anos, de modo a conferir maior resistência mecânica. Além disso, selecionaram-se as que não possuíam agentes patológicos.

O corte foi realizado com o uso de motosserras na parte inferior da barra, com posterior esforço de tração em um ponto cerca de $20 \mathrm{~cm}$ acima do corte. Isto foi realizado com um trator, que tracionava uma corda amarrada a ele. Posteriormente cortaram-se as barras no tamanho desejado, também com a motosserra, porém com uma folga de $20 \mathrm{~cm}$ de cada lado, devido aos futuros esculpimentos nas extremidades, necessários para realizar as ligações entre as peças. Além disso, cortou-se uma barra a mais de cada tamanho, para servir de reserva.

$\mathrm{Na}$ figura 10 são comparadas três das principais condições das barras de bambu, onde a letra $\mathrm{A}$ representa uma barra que está apropriada para uso estrutural, pois aparenta ter entre 3 e 6 anos de idade, sem apresentar agentes patológicos. A barra com a letra B corresponde a um bambu ainda muito jovem, com menos de 3 anos de idade, ainda em crescimento, portanto não poderá ser utilizado para fins estruturais. A barra com a letra $\mathrm{C}$ tem a aparência de ter uma idade bem superior a 6 anos, devido a quantidade de fungos na sua superfície.
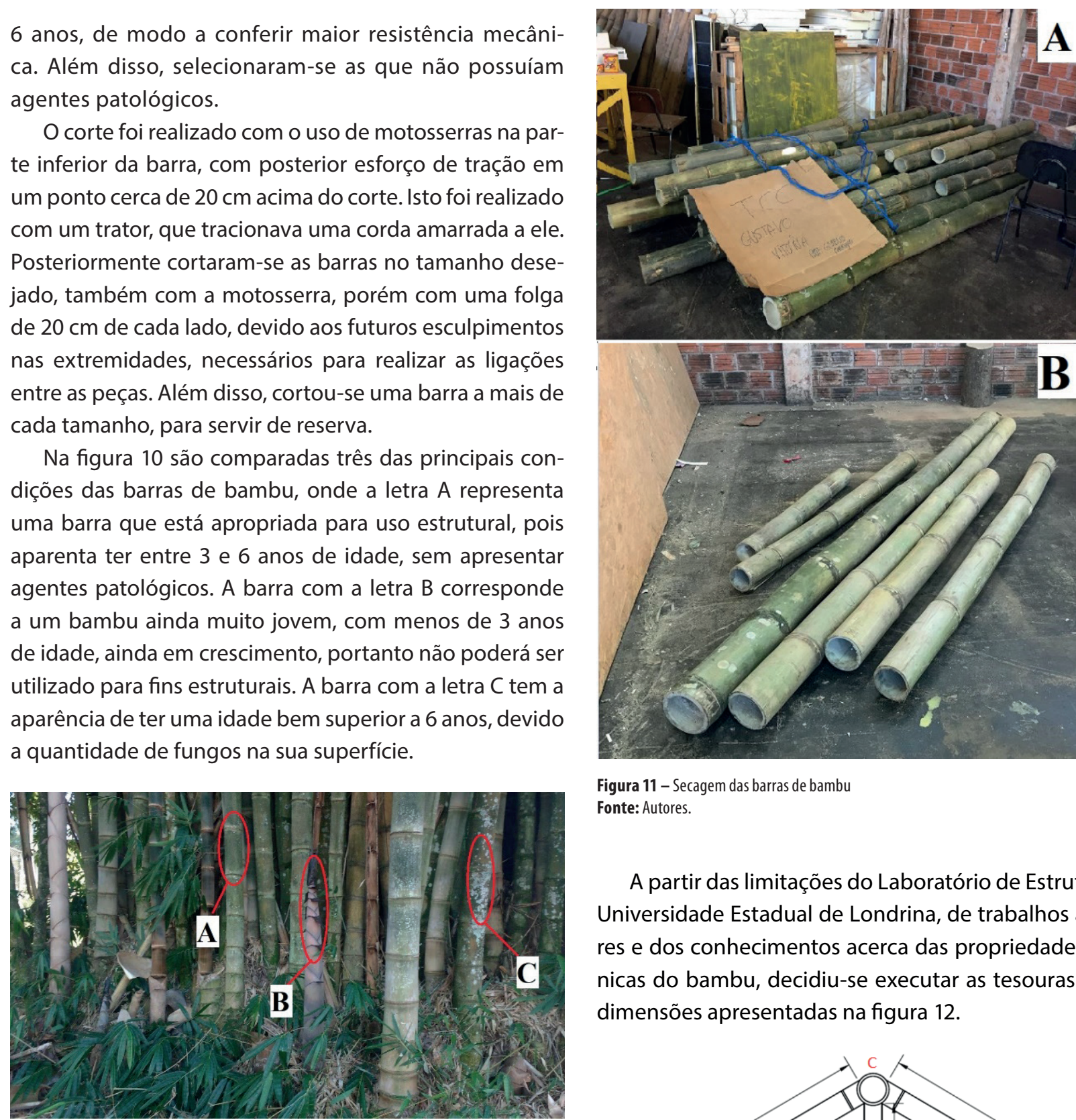

Figura 11 - Secagem das barras de bambu Fonte: Autores.

A partir das limitações do Laboratório de Estruturas da Universidade Estadual de Londrina, de trabalhos anteriores e dos conhecimentos acerca das propriedades mecânicas do bambu, decidiu-se executar as tesouras com as dimensões apresentadas na figura 12.

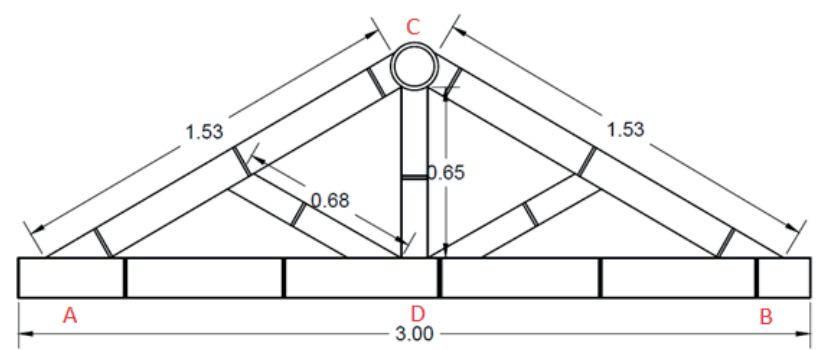

Figura 12 - Configuração das tesouras executadas Fonte: Autores. das outras, seguindo as limitações de biente, com o intuito de acelerar o procedimento de perda da umidade.

Foi necessário esperar três meses para uma secagem apropriada (figura 11-A e figura 11-B). Nota-se, nas referidas figuras, a acentuada diminuição da coloração esverdeada, indicando que as barras da figura 11-B já estavam aptas para o início da execução das tesouras.

Os apoios A e B foram reforçados com graute e com dois tipos de abraçadeiras metálicas: A "fita furada", conforme a figura 13-A, nas tesouras 1, 2 e 3; e a "fita padrão", ilustrado na figura 13-B, nas tesouras 4, 5 e 6 . As ligações entre as barras das tesouras foram realizadas com barras roscadas, como apresentado na figura 14. 


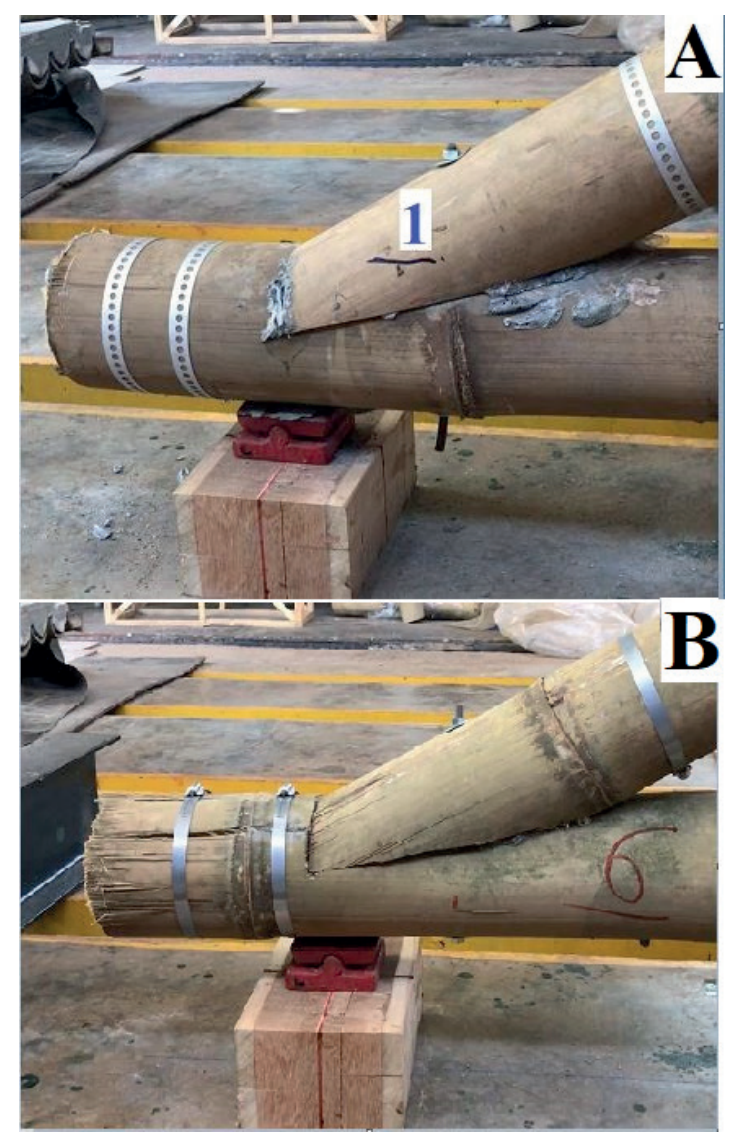

Figura 13 - Configurações dos apoios das tesouras Fonte: Autores.

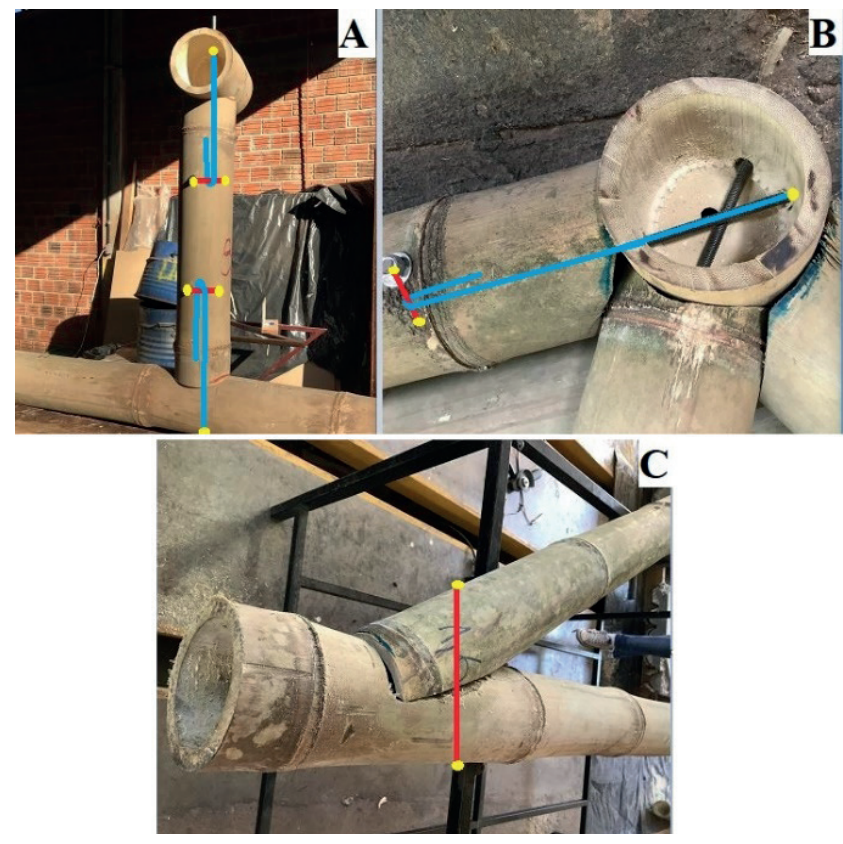

Figura 14 - Ligaçōes efetuadas com barras roscadas de aço Fonte: Autores.

O graute foi a opção escolhida como material de preenchimento dos apoios das tesouras, devido a sua elevada fluidez e elevada resistência característica à compressão de $50 \mathrm{MPa}$. Estas duas características são essenciais, pois este material é capaz de preencher com facilidade os colmos do bambu, bem como contribuir consideravelmente na resistência mecânica dos apoios das tesouras.

Para preencher com graute a região dos apoios, as tesouras foram colocadas em posição invertida em uma estrutura provisória de madeira, conforme ilustrado na figura 15. A concretagem se deu por inserção de graute em furos de $4 \mathrm{~cm}$ de diâmetro na parte inferior da ligação dos apoios. Estes furos estão destacados e numerados de 1 a 12. A vedação, que se mostrou eficiente na maioria das vezes, se deu por uso de plástico bolha e da fita adesiva.

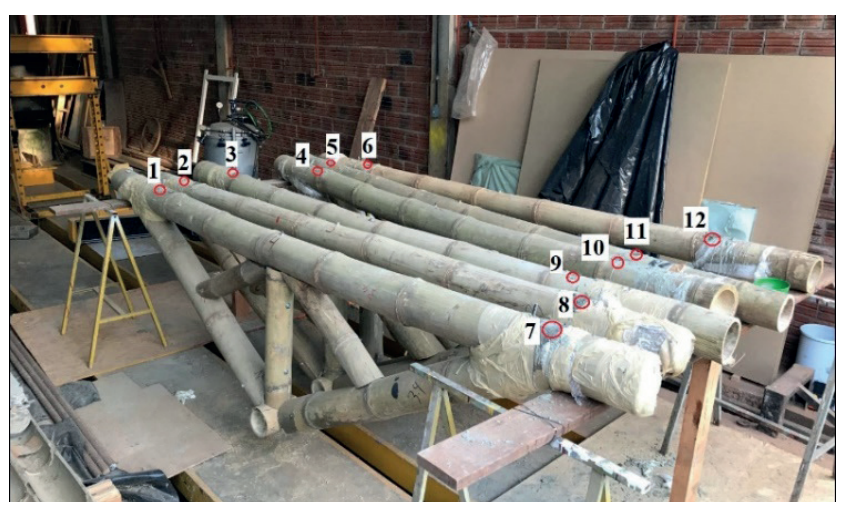

Figura 15 - Concretagem dos apoios das tesouras Fonte: Autores.

As tesouras foram vinculadas com um apoio de $1^{\circ}$ gênero (figura 16-A), e outro de $2^{\circ}$ gênero (figura 16-B), garantindo que a estrutura se comportasse estruturalmente como isostática. A vantagem desta configuração é que os deslocamentos horizontais da tesoura são absorvidos pelo apoio.
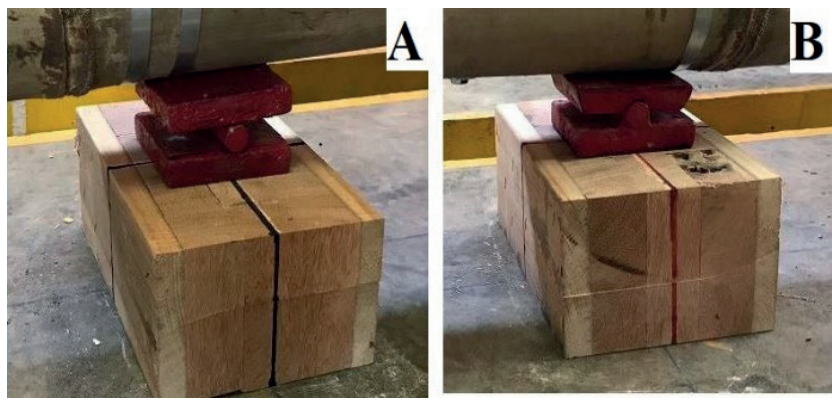

Figura 16 - Apoios das tesouras Fonte: Autores.

Após a montagem e a aplicação do reforço nos apoios, as tesouras foram posicionadas no pórtico, onde foram aplicadas as cargas concentradas no nó superior da tesoura, conforme a foto da figura 17. 


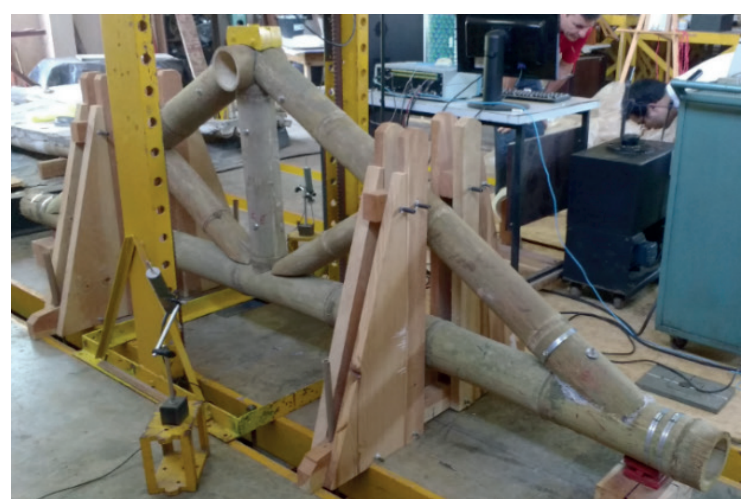

Figura 17 - Tesoura posicionada no pórtico para realização do ensaio Fonte: Autores.

Os deslocamentos foram medidos através de transdutores de deslocamento LVDT (Linear Voltage Differential Transformer). O funcionamento do referido aparelho consiste em empurrar a haste em direção ao próprio apareIho, pois é com o posterior alívio de força que as medições são efetuadas.

Foram instalados três destes sensores em cada tesoura, sendo dois na parte inferior e um na parte superior, conforme fotos da figura 18.

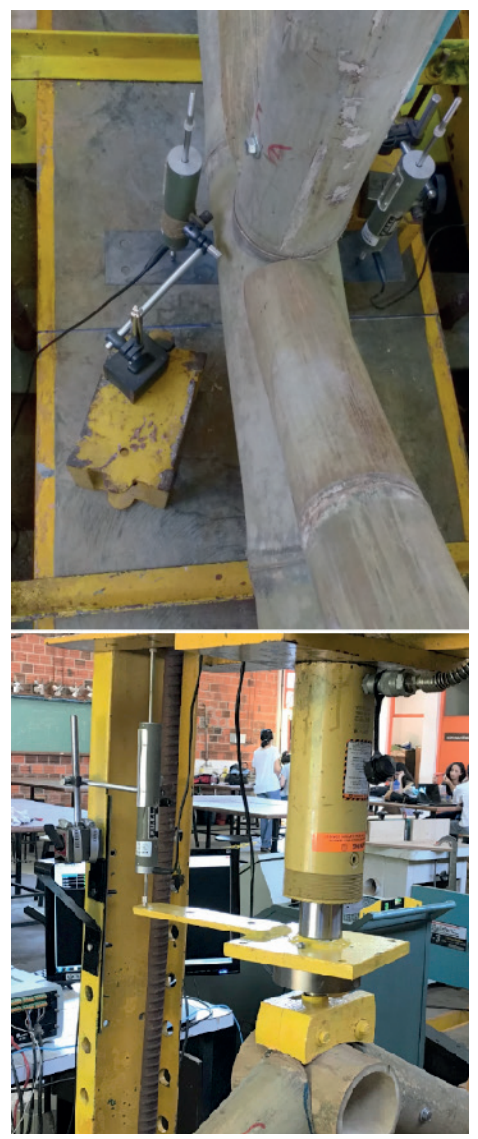

Figura 18 - Disposição dos sensores de deslocamento nas tesouras

Fonte: Autores.
Os valores da carga aplicada e dos deslocamentos dos 3 sensores, medidos desde o início do ensaio até a ruptura de cada tesoura, foram armazenados simultaneamente em arquivos.

Com o objetivo de verificar se as tesouras ensaiadas poderiam ser utilizadas em coberturas de edificações, foram determinados os carregamentos, ou seja, o peso próprio de seus elementos, a sobrecarga, e as ações do vento. Para tanto, foram estudados dois tipos de coberturas, para dois extremos usuais da distância entre tesouras, conforme se descreve a seguir.

a) Telhas cerâmicas, ripas, caibros e terças de madeira e tesouras de bambu

I) Distância entre tesouras de $2,5 \mathrm{~m}$

II) Distância entre tesouras de 5,0 m

b) Telhas termoacústicas, terças de madeira e tesouras de bambu

I) Distância entre tesouras de $2,5 \mathrm{~m}$

II) Distância entre tesouras de 5,0 m

Para permitir a comparação dos carregamentos atuantes em uma cobertura de aplicação prática com os carregamentos utilizados nos ensaios experimentais das seis tesouras de bambu, é necessário transformar o carregamento de superfície (combinação de ações de cargas permanentes e acidentais) em uma carga pontual aplicada no ponto superior central da tesoura. Um esquema ilustrativo desse procedimento pode ser visto na figura 19.

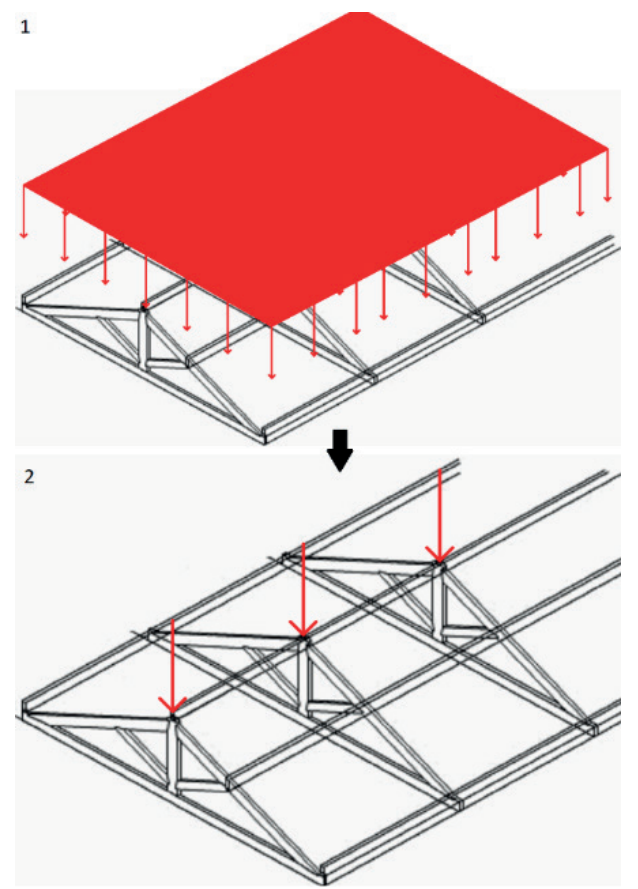

Figura 19 - Carga superficial transformada em uma carga pontual (ref. ao ensaio) Fonte: Autores. 
A partir da obtenção das cargas pontuais equivalentes, conforme descrito acima, referente aos dois tipos de cobertura citados, é analisada a segurança das tesouras ensaiadas de bambu quanto ao Estado Limite Último (E.L.U.) e quanto ao Estado Limite de Serviço (E.L.S.).

\section{RESULTADOS E DISCUSSÕES}

Realizados os ensaios experimentais, foram obtidos os dados de carga última de ruptura e de deslocamentos. A tabela 1 apresenta os resultados máximos para as 6 tesouras.

\begin{tabular}{|l|l|l|}
\hline Tesoura & $\begin{array}{l}\text { Carga última } \\
\text { experimental (tf) }\end{array}$ & $\begin{array}{l}\text { Deslocamento } \\
\text { máximo }(\mathbf{m m})\end{array}$ \\
\hline 1 & 4,76 & 45,5 \\
\hline 2 & 4,26 & 34,6 \\
\hline 3 & 3,72 & 36,7 \\
\hline 4 & 6,57 & 37,4 \\
\hline 5 & 5,16 & 56,2 \\
\hline 6 & 4,90 & 54,9 \\
\hline
\end{tabular}

Tabela 1 - Dados experimentais das tesouras Fonte: Autores.

Nota-se dos resultados acima que a técnica mais eficiente de reforço nos apoios foi aquela onde foram utilizadas as braçadeiras do tipo "fita padrão", pois as tesouras 4, 5 e 6, que utilizaram esta técnica, apresentaram melhores resultados que as outras três tesouras, que tiveram a utilização de "fitas furadas". Isto se deve à maior resistência da "fita padrão" se comparadas com as "fitas furadas".

Todas as seis tesouras romperam devido ao cisaIhamento em um dos seus apoios, sendo que a ruptura ocorre nos apoios de menor área de cisalhamento de cada tesoura.

Na figura 20 se apresentam os diagramas carga $x$ deslocamento, medidos nas tesouras 1, 2 e 3, respectivamente.

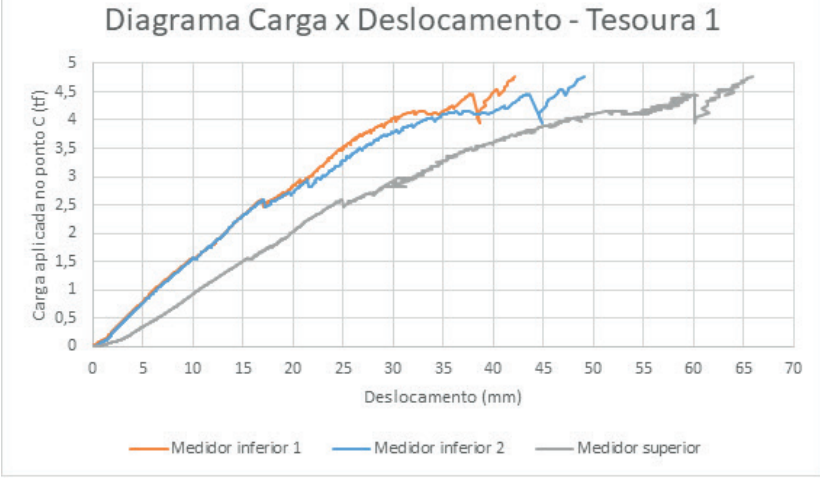

Diagrama Carga x Deslocamento - Tesoura 2

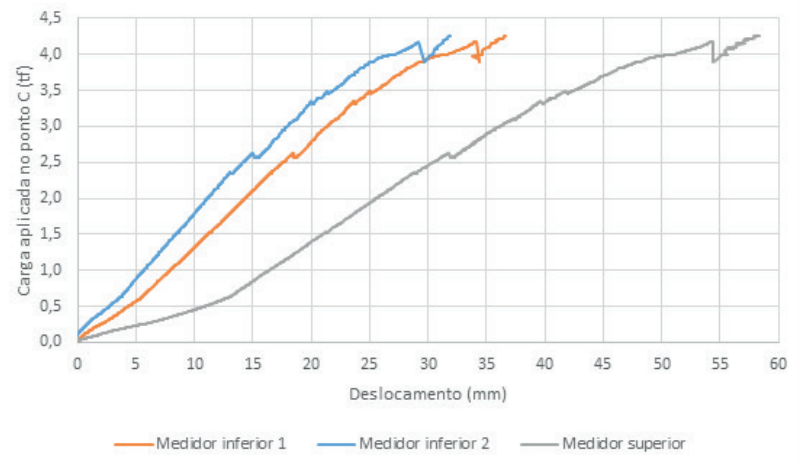

Diagrama Carga x Deslocamento - Tesoura 3

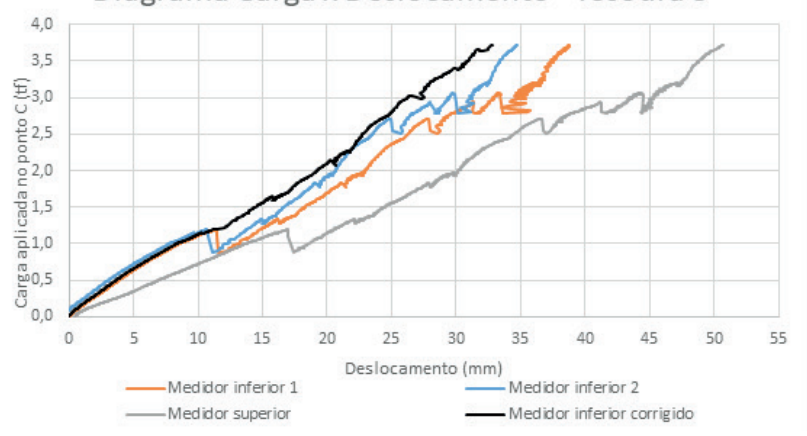

Figura 20 - Diagrama carga x deslocamento das tesouras 1, 2 e 3 Fonte: Autores.

Percebe-se que o comportamento mecânico das tesouras é muito próximo ao da Lei de Hooke, até certo nível de carregamento, sendo que quando os mecanismos resistentes da tesoura começam a falhar, acontecem acomodações na tesoura e consequentes irregularidades nas curvas.

As tesouras 1 e 2 tiveram um comportamento normal na ruptura, ao contrário da tesoura 3 , que teve um problema no ensaio, onde o pistão da máquina de aplicação de força atingiu seu limite de deslocamento antes que a que a tesoura atingisse a ruptura.

Percebe-se nos gráficos da figura 20 e da figura 21, que as curvas referentes ao medidor de deslocamento superior, apesar de ter um comportamento similar, tem uma discrepância em relação aos dois medidores de 
deslocamentos inferiores. Esta discrepância se deve ao fato de que o colmo de aplicação de força no ponto superior da tesoura sofre com um esmagamento.

As tesouras 4, 5 e 6 foram executadas com a abraçadeira tipo "fita padrão". Os respectivos diagramas carga x deslocamento das referidas tesouras estão mostrados na figura 21.

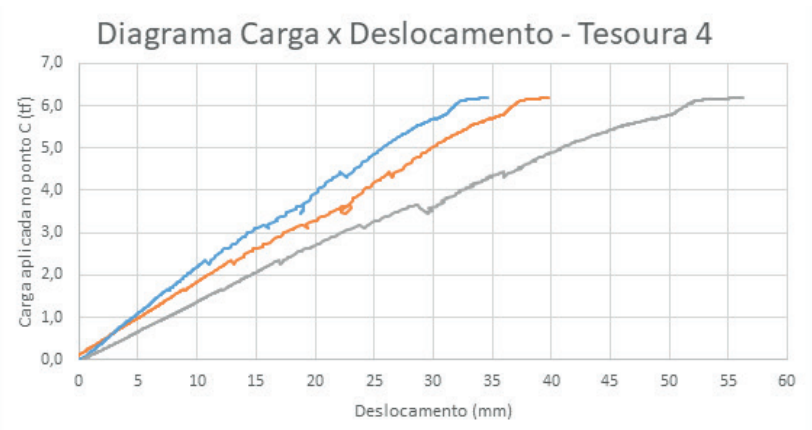

— Medidor inferior 1 - tentativa 1 - Medidor inferior 2- tentativa 1 -Medidor superior - tentativa 1

Diagrama Carga x Deslocamento - Tesoura 5

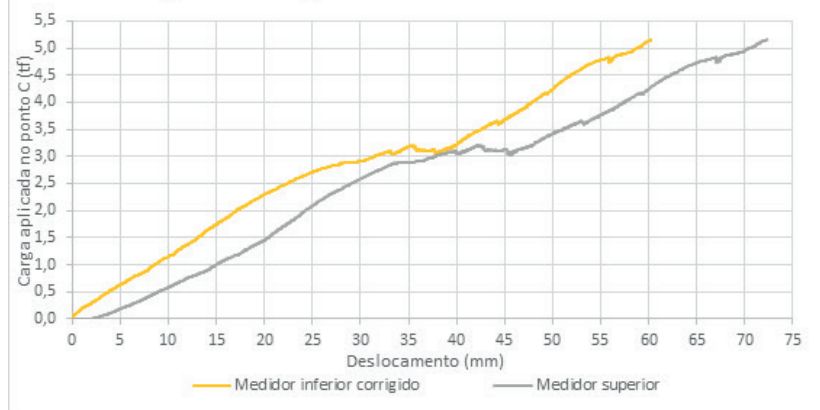

Diagrama Carga x Deslocamento - Tesoura 6

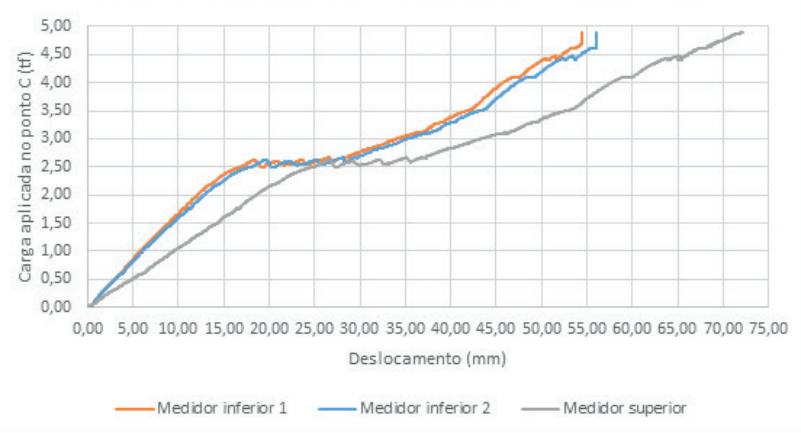

Figura 21 - Diagrama carga x deslocamento das tesouras 4, 5 e 6 Fonte: Autores.

Diferentemente do comportamento observado nas outras tesouras, as curvas carga $x$ deslocamento das tesouras 5 e 6 apresentaram um patamar. Esse fenômeno está associado ao fato de que o graute não preencheu todo o espaço interno do bambu na fase da execução das tesouras, ocorrendo um esmagamento do colmo do apoio da tesoura durante o ensaio experimental.

No item "4.1" abaixo são apresentadas as principais técnicas construtivas para se obter uma tesoura em bambu de máxima eficiência estrutural, enquanto que no item " 4.2 " é verificado se as tesouras em bambu ensaiadas no laboratório podem ser utilizadas em coberturas usuais, propondo dois tipos de cobertura.

\subsection{Proposta de uma tesoura em bambu de má- xima eficiência estrutural}

Nas fotos das figuras 22-A, 22-B e 22-C estão ilustradas três situações distintas encontradas durante a realização dos ensaios: na figura 22-A o apoio que sofreu ruptura da tesoura 1, na iminência do colapso; na figura 22-B o apoio que sofreu ruptura da tesoura 6 , na iminência do colapso; e na figura 22-C o apoio que sofreu ruptura da tesoura 4, na iminência colapso.
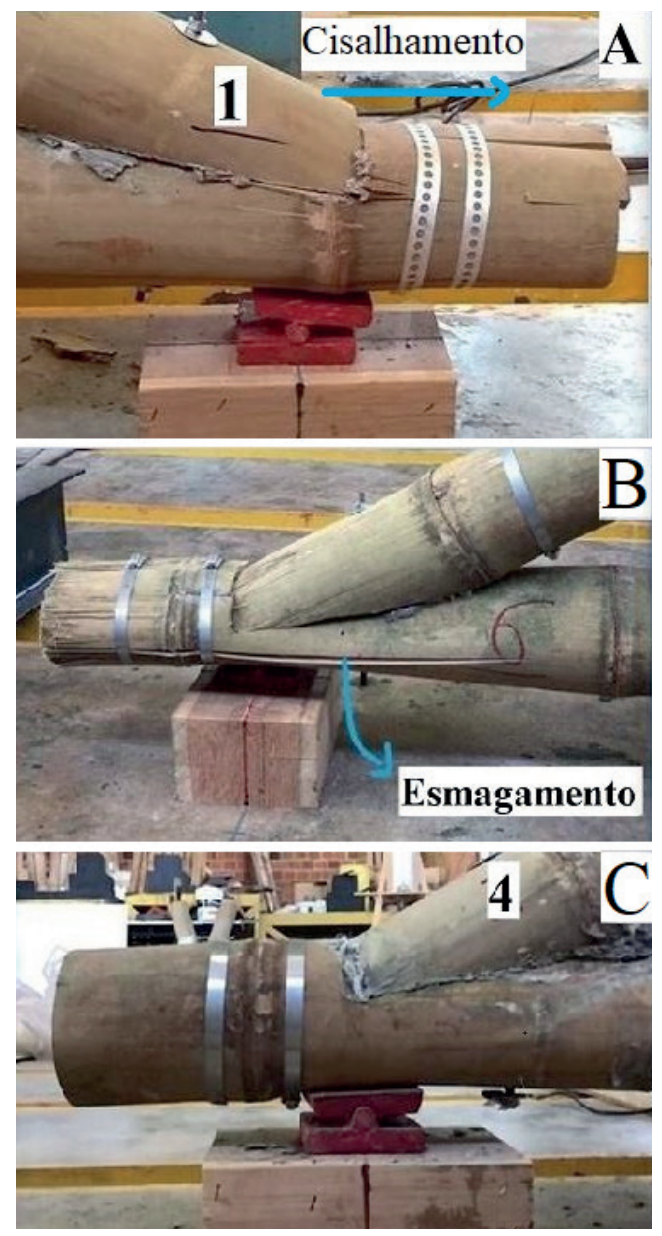

Figura 22 - Três situações distintas capturadas na iminência da ruptura Fonte: Autores.

Nota-se na figura 22-A (tesoura 1) que o banzo superior transfere a carga tanto para o bambu (cisalhamento) quanto para o graute (compressão diametral). $O$ problema desta situação está no fato do bambu (banzo inferior) ser solicitado diretamente ao cisalhamento, diminuindo a resistência da tesoura como um todo. Além disso, com a 
movimentação do banzo superior, a barra roscada deste apoio é solicitada à flexão. Estas referidas tensões induzem o graute a se romper precocemente. O preenchimento do graute deste apoio foi bem executado, pois não houve esmagamento entre os banzos nesta região.

Já na figura 22-B (tesoura 6) percebe-se que o banzo superior incide apenas no graute do banzo inferior, pois o bambu não está sendo solicitado ao cisalhamento. Isto tende a ocorrer quando o diâmetro externo do banzo superior é de pelo menos 0,01 $\mathrm{m}$ menor que o inferior. $\mathrm{O}$ enchimento com graute neste apoio, no entanto foi mal executado, devido ao intenso esmagamento entre os banzos. Apesar de não ter ocorrido o cisalhamento verificado na tesoura 1, outro problema ocorreu: devido à má execução, a seção transversal de graute na região do apoio foi bastante reduzida, perdendo assim a resistência mecânica deste apoio.

A tesoura 4, ilustrada na figura 22-C, teve uma carga de ruptura consideravelmente maior que as outras tesouras, pois, além do graute de seus apoios ter sido bem executado, o banzo superior incidiu diretamente no graute do banzo inferior. Desta forma, a resistência mecânica do graute foi totalmente aproveitada. Isto pode ser comprovado pela ausência de cisalhamento e esmagamento na região do apoio até a iminência da ruptura. Esta é, portanto, a principal técnica construtiva que deve ser aplicada para se obter uma tesoura em bambu de máxima eficiência estrutural.

O diafragma, quando mantido intacto na região do apoio, confere grande resistência ao esmagamento e ao cisalhamento, e auxilia no confinamento do graute. Esta importante técnica construtiva, de forma análoga ao que foi visto anteriormente, também pertence à tesoura 4 . Ou seja, o conjunto graute-barra roscada, confinado pelo bambu e pelas abraçadeiras é o procedimento metodológico que mais contribui para o ganho de resistência mecânica dos apoios das tesouras.

O correto alinhamento dos banzos superiores com os apoios de $1^{\circ}$ e $2^{\circ}$ gênero favorece uma compressão direta no graute confinado no banzo inferior. Esta também é uma característica apresentada pela tesoura 4, conforme apresentado pela reta em laranja na figura 23.

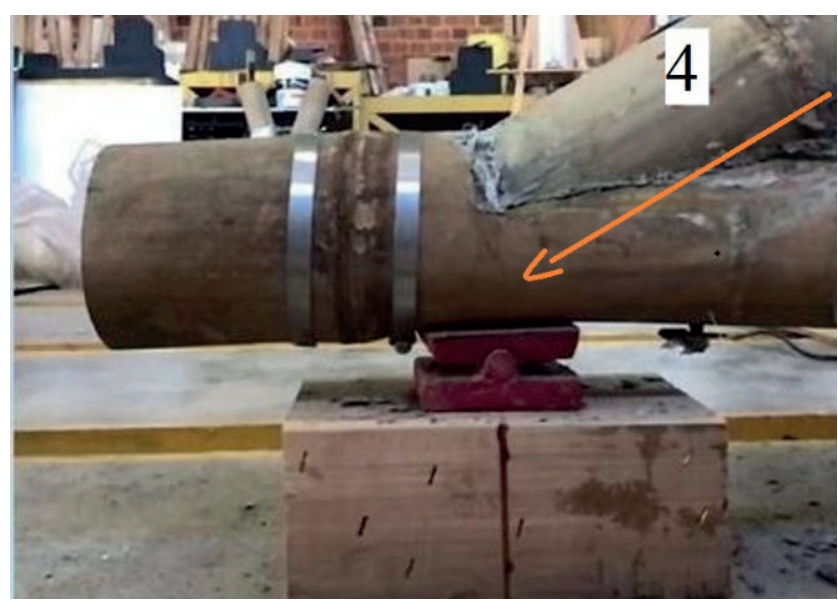

Figura 23 - Alinhamento do banzo superior com 0 apoio Fonte: Autores.

As tesouras 5 e 6 apresentaram um importante esmagamento entre os banzos na região do apoio da tesoura, devido a um preenchimento mal executado do graute no interior do bambu. Esta situação provavelmente seria amenizada com a inserção de uma abraçadeira antes do encontro entre os dois banzos, conforme se pode observar nas fotos das figuras 24-A e 24-B.

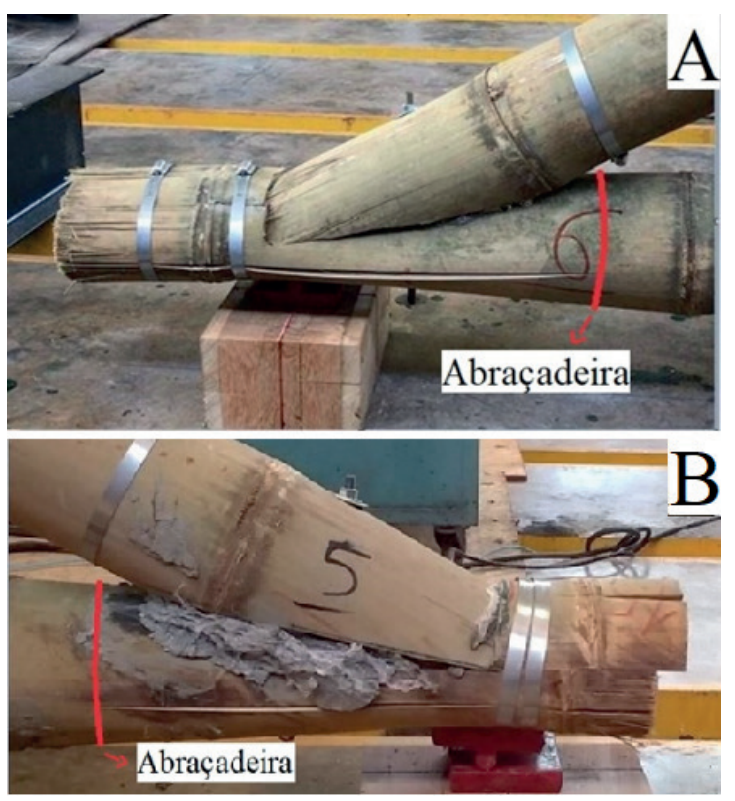

Figura 24 - Proposta de inserção de uma quarta abraçadeira na região do apoio Fonte: Autores.

Com as técnicas construtivas analisadas anteriormente, é possível determinar as especificações de uma tesoura em bambu de máxima eficiência estrutural. Esta concepção está ilustrada na figura 25. 


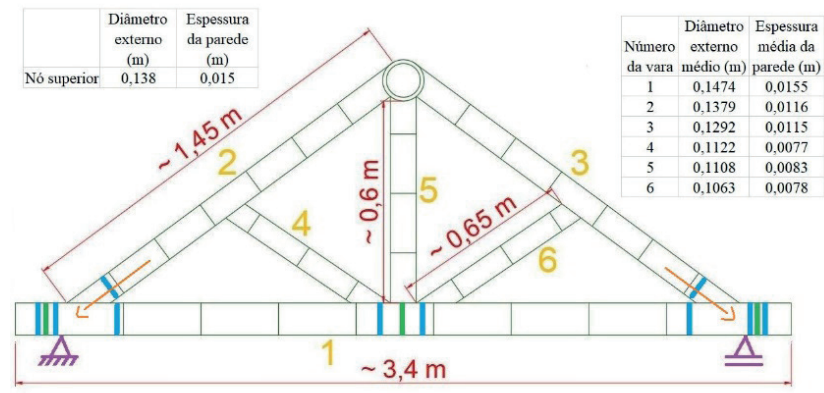

Figura 25 - Concepção de uma tesoura em bambu de máxima eficiência estrutural Fonte: Autores.

As dimensões apresentadas são as da tesoura 4, pois foi a tesoura que mais se aproximou desta concepção. Estas medidas possibilitaram que os banzos superiores incidissem diretamente no graute dos apoios. Os três diafragmas de bambu que devem ser mantidos intactos, situados no banzo inferior, estão destacados em verde. As abraçadeiras estão destacadas em azul, sendo quatro por apoio e duas na região central do banzo inferior. Destaca-se também o alinhamento dos banzos superiores com os apoios de $1^{\circ}$ e $2^{\circ}$ gênero pelas retas em laranja.

\subsection{Verificação da aplicação prática da tesoura de bambu}

Com o objetivo de verificar se as tesouras em bambu ensaiadas no laboratório podem ser utilizadas em coberturas usuais, a seguir é realizada uma simulação para duas situações de utilização em edificações, onde em ambos os casos é utilizado o mesmo vão das tesouras ensaiadas ( $3 \mathrm{~m}$ ), e duas distâncias extremas entre tesouras, de $2,5 \mathrm{~m}$ e $5,0 \mathrm{~m}$.

a) Cobertura com telha cerâmica, terças, caibros e ripas em madeira:

Os elementos em madeira do telhado (ripa, caibro e terça) foram verificados quanto ao E.L.U e quanto ao E.L.S, sendo que se adotou as dimensões comerciais expostas na tabela 2 .

\begin{tabular}{|l|l|l|}
\hline Elemento & $\begin{array}{l}\text { Dimensões para } \\
\text { vão = 2,5 } \mathbf{~}\left(\mathbf{c m}^{\mathbf{2}}\right)\end{array}$ & $\begin{array}{l}\text { Dimensões para } \\
\text { vão }=\mathbf{5} \mathbf{~ m}\left(\mathbf{c m}^{\mathbf{2}}\right)\end{array}$ \\
\hline Ripa & $2,0 \times 2,5$ & $2,0 \times 2,5$ \\
\hline Caibro & $4,5 \times 5,0$ & $4,5 \times 5,0$ \\
\hline Terça & $8,0 \times 12,0$ & $13,0 \times 20,0 \mathrm{~cm}$ \\
\hline
\end{tabular}

Tabela 2 - Dimensões dos elementos em madeira Fonte: Autores.
As dimensões médias do diâmetro externo e da espessura das barras das tesouras de bambu, da espécie Dendrocalamus giganteus, encontram-se indicadas na tabela 3.

\begin{tabular}{|l|l|l|}
\hline Barra & $\begin{array}{l}\text { Diâmetro ex- } \\
\text { terno } \mathbf{( c m})\end{array}$ & Espessura $\mathbf{( c m )}$ \\
\hline 1 & 15,5 & 1,5 \\
\hline 2 e 3 & 14,0 & 1,3 \\
\hline 4,5 e 6 & 12,0 & 1,0 \\
\hline
\end{tabular}

Tabela 3 - Dimensões das barras da tesoura Fonte: Autores.

Considerando que os pesos específicos dos materiais utilizados, da madeira de $950 \mathrm{kgf} / \mathrm{m}^{3}$, do bambu de 800 $\mathrm{kgf} / \mathrm{m}^{3}$, e do graute de $2200 \mathrm{kgf} / \mathrm{m}^{3}$, as cargas distribuídas para cada elemento estrutural estão indicadas na tabela 4.

\begin{tabular}{|l|l|l|}
\hline $\begin{array}{l}\text { Cargas (pesos } \\
\text { próprios) }\end{array}$ & $\begin{array}{l}\text { Carga para } \\
\text { vão= 2,5 } \mathbf{~} \\
\left(\mathbf{k g f} / \mathbf{m}^{\mathbf{2}} \text { ) }\right.\end{array}$ & $\begin{array}{l}\text { Carga para } \\
\text { vão= 5 } \\
\left(\mathbf{k g f} / \mathbf{m}^{\mathbf{2}} \mathbf{)}\right.\end{array}$ \\
\hline Telha cerâmica & 43,20 & 43,20 \\
\hline Ripa de madeira & 1,19 & 1,19 \\
\hline Caibro de madeira & 4,37 & 4,37 \\
\hline Terça de madeira & 12,16 & 32,93 \\
\hline Tesoura de bambu & 9,96 & 4,98 \\
\hline $\begin{array}{l}\text { Total cargas } \\
\text { permanentes }\end{array}$ & 70,87 & 86,67 \\
\hline Sobrecarga & 25,00 & 25,00 \\
\hline $\begin{array}{l}\text { Vento de } \\
\text { sobrepressão }\end{array}$ & 4,82 & 4,82 \\
\hline Vento de sucção & 61,76 & 61,76 \\
\hline
\end{tabular}

Tabela 4 - Cargas atuantes na tesoura de bambu Fonte: Autores.

Utilizando os parâmetros normativos, para a região de Londrina-PR, obteve-se uma carga de $4,82 \mathrm{kgf} / \mathrm{m}^{2}$ para o vento de sobrepressão, e de $61,76 \mathrm{kgf} / \mathrm{m}^{2}$ para o vento de sucção.

Na tabela 5 estão indicadas as cargas concentradas equivalentes ao carregamento distribuído atuante na superfície da cobertura, considerando as distâncias entre tesouras de $2,5 \mathrm{~m}$ e $5 \mathrm{~m}$, para um vão da tesoura de $3 \mathrm{~m}$. 


\begin{tabular}{|l|l|l|}
\hline $\begin{array}{l}\text { Carga pontual } \\
\text { equivalente }(\mathbf{k g f})\end{array}$ & Vão=2,5 $\mathbf{~}$ & Vão=5 m \\
\hline $\begin{array}{l}\text { Cargas } \\
\text { permanentes }\end{array}$ & 531,56 & 1300,00 \\
\hline Sobrecarga & 187,50 & 375,00 \\
\hline $\begin{array}{l}\text { Vento de } \\
\text { sobrepressão }\end{array}$ & 36,19 & 72,37 \\
\hline Vento de sucção & 463,17 & 926,34 \\
\hline
\end{tabular}

Tabela 5 - Cargas pontuais equivalente ao carregamento da superfície da cobertura Fonte: Autores.

Assim, têm-se as seguintes combinações de ações para o estado limite último, para a cobertura com vãos entre tesouras de $2,5 \mathrm{~m}$ :

$Q_{d 1}=1,3 .(531,56)+1,4 .(187,50)=953,52 \mathrm{kgf}$

$Q_{d 2}=1,3 \cdot(531,56)+1,4 \cdot(187,50)+1,4 \cdot 0,5 \cdot(36,19)=978,85 \mathrm{~kg} f$

$Q_{d 3}=1,3 \cdot(531,56)+1,4 \cdot 0,75 \cdot(36,19)+1,4 \cdot 0,4 \cdot(187,50)=834,02 \mathrm{kgf}$

$Q_{d 4}=1,3 \cdot(531,56)+1,4 \cdot 0,75 \cdot(-463,17)=204,69 \mathrm{kgf}$

E as seguintes combinações de ações para o estado limite último, para a cobertura com vãos entre tesouras de $5 \mathrm{~m}$ :

\begin{tabular}{|l|l|l|}
\hline $\begin{array}{l}\text { Cargas (pesos } \\
\text { próprios) }\end{array}$ & $\begin{array}{l}\text { Carga para } \\
\text { vão= 2,5 } \mathbf{~} \\
\left(\mathbf{k g f} / \mathbf{m}^{\mathbf{2}}\right)\end{array}$ & $\begin{array}{l}\text { Carga para } \\
\text { vão= 5 } \mathbf{~ m} \\
\left(\mathbf{k g f} / \mathbf{m}^{\mathbf{2}}\right)\end{array}$ \\
\hline $\begin{array}{l}\text { Telha } \\
\text { termoacústica }\end{array}$ & 5,96 & 5,96 \\
\hline Terça de madeira & 6,08 & 20,27 \\
\hline Tesoura de bambu & 9,96 & 4,98 \\
\hline $\begin{array}{l}\text { Total cargas } \\
\text { permanentes }\end{array}$ & 22,00 & 31,21 \\
\hline Sobrecarga & 25,00 & 25,00 \\
\hline $\begin{array}{l}\text { Vento de } \\
\text { sobrepressão }\end{array}$ & 4,82 & 4,82 \\
\hline Vento de sucção & 61,82 & 61,82 \\
\hline
\end{tabular}

Tabela 6 - Cargas atuantes na tesoura com telhas termoacústicas Fonte: Autores.

O peso próprio da tesoura de bambu, o vento e a sobrecarga são considerados da mesma forma que o item anterior.

Na tabela 7 estão indicadas as cargas concentradas equivalentes ao carregamento distribuído atuante na superfície da cobertura, considerando as distâncias entre tesouras de $2,5 \mathrm{~m}$ e $5 \mathrm{~m}$, para um vão da tesoura de $3 \mathrm{~m}$.

\begin{tabular}{|l|l|l|}
\hline $\begin{array}{l}\text { Carga pontual } \\
\text { equivalente (kgf) }\end{array}$ & Vão=2,5 $\mathbf{~ m}$ & Vão=5 m \\
\hline $\begin{array}{l}\text { Cargas } \\
\text { permanentes }\end{array}$ & 165,01 & 468,11 \\
\hline Sobrecarga & 187,50 & 375,00 \\
\hline $\begin{array}{l}\text { Vento de } \\
\text { sobrepressão }\end{array}$ & 36,19 & 72,37 \\
\hline Vento de sucção & 463,17 & 926,34 \\
\hline
\end{tabular}

Desta forma, o valor da carga pontual crítica equivalente às cargas distribuídas atuantes na cobertura, aplicada no ponto superior da tesoura, é de $978,85 \mathrm{~kg} f \cong 0,98 \mathrm{tf}$, quando a distância entre tesouras é de 2,5 m, e de 2265,66 $k g f \cong 2,27 t f$, quando a distância entre vãos é de $5 \mathrm{~m}$.

Portanto, as cargas de ruptura medidas nas tesouras ensaiadas são no mínimo $435 \%$ maiores que a carga pontual teórica obtida para o vão de $2,5 \mathrm{~m}, 188 \%$ maiores para o vão de $5 \mathrm{~m}$.

b) Cobertura com telha termoacústicas (sanduíche) e terça em madeira:

Realizando a verificação da terça quanto ao E.L.U. e quanto ao E.L.S., obtêm-se dimensões de $6 \mathrm{~cm}$ de base e $8 \mathrm{~cm}$ de altura, quando a distância entre tesouras é de 2,5 $\mathrm{m}$, e de $10 \mathrm{~cm}$ por $16 \mathrm{~cm}$ quando a distância entre tesouras é de $5 \mathrm{~m}$. A tesoura de bambu tem as mesmas dimensões expostas na tabela 3. As cargas atuantes neste tipo de cobertura são apresentadas na tabela 6 .

Tabela 7 - Cargas pontuais equivalentes ao carregamento da superfície Fonte: Autores.

Com isso, têm-se as seguintes combinações de ações para o estado limite último para a cobertura com vãos entre tesouras de $2,5 \mathrm{~m}$ :

$$
\begin{aligned}
& Q^{*}{ }_{d 1}=1,3 \cdot(165,01)+1,4 \cdot(187,50)=477,02 \mathrm{kgf} \\
& Q^{*}{ }_{d 2}=1,3 \cdot(165,01)+1,4 \cdot(187,50)+1,4 \cdot 0,5 \cdot(36,19)=502,35 \mathrm{kgf} \\
& Q^{*}{ }_{d 3}=1,3 \cdot(165,01)+1,4 \cdot 0,75 \cdot(36,19)+1,4 \cdot 0,4 \cdot(187,50)=357,51 \mathrm{kgf} \\
& Q^{*}{ }_{d 4}=1,3 \cdot(165,01)+1,4 \cdot 0,75 \cdot(-463,17)=-238,81 \mathrm{~kg} f
\end{aligned}
$$


$E$ as seguintes combinações de ações para o estado limite último, para a cobertura com vãos entre tesouras de $5 \mathrm{~m}$ :

$$
\begin{aligned}
& Q^{*^{\prime}}{ }_{d 1}=1,3 \cdot(468,11)+1,4 \cdot(375,00)=1133,55 \mathrm{kgf} \\
& Q^{*^{\prime}}=1,3 \cdot(468,11)+1,4 \cdot(375,00)+1,4 \cdot 0,5 \cdot(72,37)=1184,21 \mathrm{kgf} \\
& Q^{*^{\prime}}{ }_{d 3}=1,3 \cdot(468,11)+1,4 \cdot 0,75 \cdot(72,37)+1,4 \cdot 0,4 \cdot(375,00)=894,53 \mathrm{kgf} \\
& Q^{*^{\prime}}{ }_{d 4}=1,3 \cdot(468,11)+1,4 \cdot 0,75 \cdot(-926,34)=-270,49 \mathrm{kgf}
\end{aligned}
$$

A combinação para o vento de sucção, neste caso, em que a cobertura é mais leve, provoca uma carga pontual negativa (para cima) na tesoura. Não se têm dados acerca da ruptura da tesoura para cargas pontuais negativas, porém é fácil perceber que a tesoura não será solicitada quanto ao cisalhamento nos seus apoios, que são os pontos mais frágeis da estrutura. Além disso, as cargas de 238,81 kgf e 270,49 kgf são pequenas em relação as cargas críticas calculadas para a estrutura.

Temos então que a carga pontual crítica, equivalente às cargas distribuídas atuantes em coberturas reais, aplicada no ponto superior de uma tesoura real é de, aproximadamente, $502,35 \mathrm{~kg} f \cong 0,50 \mathrm{tf}$, para distância entre tesouras de $2,5 \mathrm{~m}$ e de $1184,21 \mathrm{~kg} f \cong 1,18 \mathrm{tf}$ para distância entre vãos de $5 \mathrm{~m}$.

As cargas últimas das tesouras ensaiadas são de $848 \%$ a $1308 \%$ maiores que a carga pontual encontrada para o vão de 2,5 m e de $360 \%$ a $555 \%$ maiores que a carga pontual encontrada para o vão de $5 \mathrm{~m}$ (sem considerar a carga da tesoura 3, devido ao problema no ensaio).

Em relação ao deslocamento da tesoura, a NBR 71901997 considera no item 9.2.1 (Deformações limites para construções correntes) que para as construções correntes (com carregamentos usuais), a flecha limite $f_{\text {lim }}$ é de 1/200 do vão.

Dessa forma, considerando o vão de $3 \mathrm{~m}$, o deslocamento limite da tesoura é de $15 \mathrm{~mm}$.

$$
f_{l i m}=\frac{l}{200}=\frac{3000}{200}=15 \mathrm{~mm}
$$

Na figura 26 são mostrados dois gráficos, cada tipo de cobertura. Em cada gráfico são mostrados os diagramas carga $x$ deslocamento das seis tesouras ensaiadas, além da curva media (em linha preta), e duas linhas horizontais, referentes as duas cargas equivalentes calculadas quando a distância entre as tesouras é de $2,5 \mathrm{~m}$ e $5 \mathrm{~m}$.

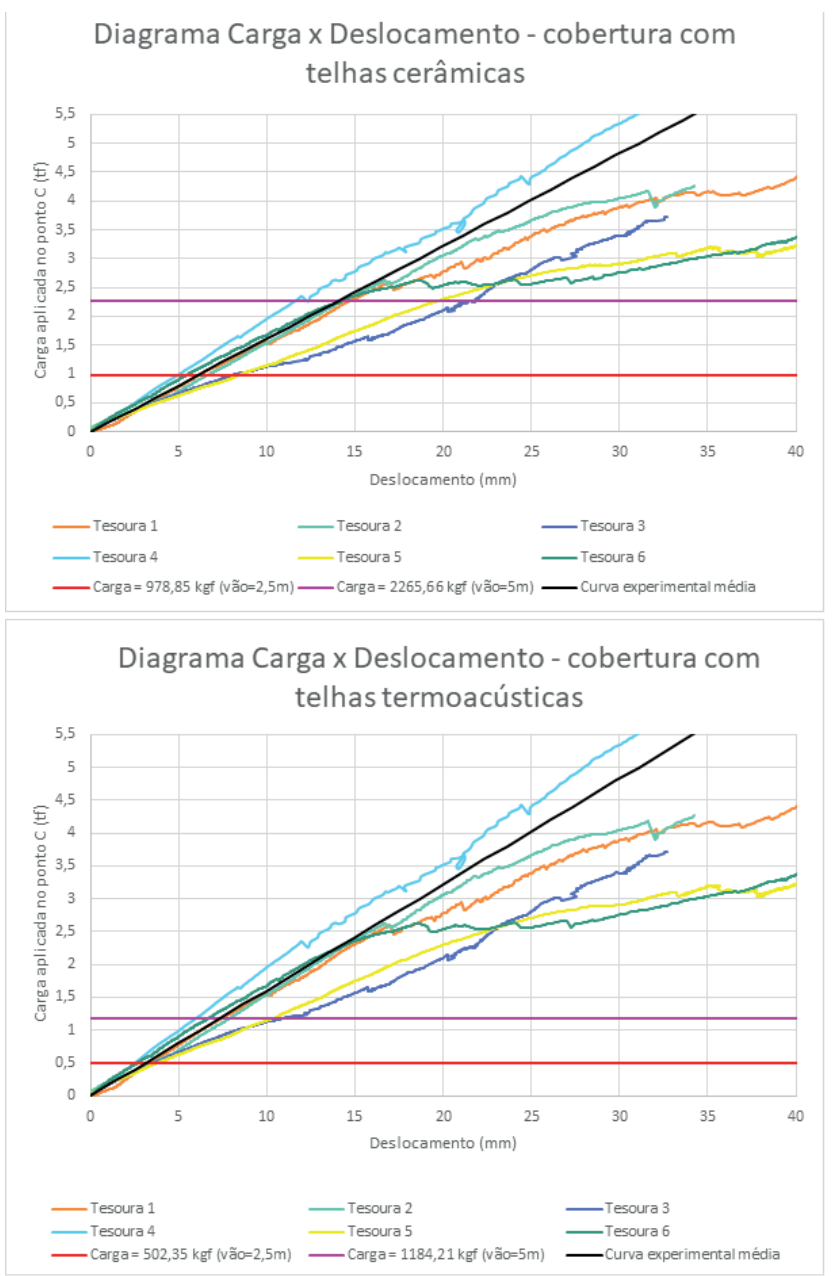

Figura 26 - Diagrama carga (tf) $x$ deslocamento $(\mathrm{mm})$ Fonte: Autores.

Na figura 26 pode-se constatar que para a cobertura com telhas cerâmicas, o deslocamento limite de $15 \mathrm{~mm}$ é ultrapassado nas tesouras 3 e 5 para a carga de 2,27 tf, porém, a curva média das tesouras está abaixo deste limite. $\mathrm{Na}$ cobertura com telhas termoacústicas, para ambos os vãos entre tesouras de $2,5 \mathrm{~m}$ e $5 \mathrm{~m}$, o deslocamento das curvas experimentais é menor que $15 \mathrm{~mm}$, satisfazendo o Estado Limite de Serviço (E.L.S.).

\section{CONSIDERAÇÕES FINAIS}

No que diz respeito a montagem da tesoura, constatou-se que o conjunto graute-barra roscada, confinado pelo bambu e pelas abraçadeiras ou fitas metálicas foi o principal elemento de resistência mecânica dos apoios das tesouras em bambu, aprimorando consideravelmente o ponto débil deste tipo de estrutura. É interessante também ressaltar as configurações mais eficientes de realização e de funcionalidade da tesoura: a) com o encaixe ideal entre os banzos inferior e superior da tesoura, tendo o colmo da barra diagonal entrando no colmo da barra 
horizontal; b) com nós (diafragmas) nos colmos suscetíveis ao cisalhamento, pois um colmo com nó tem resistência maior que um colmo sem nó; c) Com a fita padrão, pois é mais eficiente tanto em sua resistência quanto em seu manuseio, em relação à fita furada.

Quanto às cargas, para os dois tipos de telhas e para distância entre tesouras de 2,5 m a 5,0 m, constatou-se que as tesouras em bambu reforçadas resistem aos esforços internos provocados pelas cargas normativas que atuam na cobertura.

No caso dos deslocamentos da tesoura submetida aos carregamentos reais, sendo a flecha limite igual a $15 \mathrm{~mm}$ para a verificação do estado limite de serviço, para as cargas pontuais equivalentes ao carregamento superficial da cobertura, o deslocamento não ultrapassou o limite (comparando com os deslocamentos experimentais).

Assim, conclui-se que o bambu devidamente tratado contra fungos e carunchos, tendo sua durabilidade garantida, é viável para utilização estrutural nas tesouras, sendo seguras tanto para o estado limite último quanto para o estado limite de serviço, quando devidamente dimensionados. As tesouras em bambu podem ser utilizadas nas coberturas das edificações, sobretudo em substituição às tesouras de madeira, afinal o bambu é um material altanicas, além de contribuir para um desenvolvimento mais sustentável.

\section{AGRADECIMENTOS}

Aos técnicos do Laboratório de Estruturas da UEL Luís Gustavo, Carlos e Reginaldo pela ajuda na preparação e realização dos ensaios das tesouras.

\section{REFERÊNCIAS}

BARBOSA, Diogo Rodrigo; CARBONARI, Gilberto. Estudo experimental de tesouras de bambu. In: V Encontro de Sustentabilidade em Projeto, 2017, Florianópolis. ENSUS 2017. Florianópolis: UFSC, 2017. v. 1. p. 1.

CARBONARI, Gilberto. Tratamento do Bambu com Tanino. 2013. (Brasil). Patente: Privilégio de Inovação. Número do registro: BR1020130207888, título: Tratamento do Bambu com Tanino. Instituição de registro: INPI Instituto Nacional da Propriedade Industrial.

CARBONARI, Gilberto; DA SILVA JR, Nelson Matias; PEDROSA, Nícolas Henrique; ABE, Camila H.; SCHOLTZ,

Marcos F.; ACOSTA, Caio. C. V.; CARBONARI, Luana T. Propriedades Mecânicas de Várias Espécies de Bambu. In: XV EBRAMEM - Encontro Brasileiro em Madeiras e em Estruturas de Madeira, 2016, Curitiba. Anais do EBRAMEM-Encontro Brasileiro em Madeiras e em Estruturas de Madeira, 2016.

CARBONARI, Gilberto; DA SILVA JR, Nelson Matias; PEDROSA, Nícolas Henrique; ABE, Camila Hirome; SCHOLTZ, Marcos F.; ACOSTA, Caio. C. V.; CARBONARI Luana T.. Bambu - 0 aço vegetal. Mix Sustentável, v. 3, p. 17-25, 2017.

GONÇALVES, Vitória Maria. Estudo teórico e experimental de tesouras de bambu. 2018. 118 páginas. Trabalho de conclusão de curso (Graduação em Engenharia Civil) - Universidade Estadual de Londrina, Londrina, 2018.

JANSSEN, Jules J.A. Designing and Building with Bamboo. TECHNICAL REPORT NO. 20, International Network for Bamboo and Rattan 2000.

LÓPEZ, Oscar Hidalgo. Manual de construcción com bambú: construcción rural. 1.ed. Bogotá: Estudios Técnicos Colombianos Ltda, 1981.

PADOVAN, R. B. O bambu na arquitetura: design de conexões estruturais. 2010. 182f. Monografia (Especialização em Design) - Universidade Estadual Paulista "Júlio de Mesquita Filho", Bauru, 2010.

PRONI, Gustavo. Comportamento MecânicoExperimental de Tesouras em Bambu. Trabalho de Conclusão de Curso. Curso de Bacharelado em Engenharia Civil. Centro de Tecnologia e Urbanismo. Universidade Estadual de Londrina, 2018.

SÁNCHEZ QUINTERO, Carlos Andrés Desenvolvimento de uma ligação estrutural para construção com bambu Guadua. 2015. Dissertação (Mestrado). Universidade Federal de Santa Catarina, Florianópolis - SC, 2015.

VASCONCELLOS, Raphael Moras de. Cartilha de Fabricação de Móveis de Bambu. 1.ed. Maceió: Instituto do Bambu, 2004 


\section{AUTORES}

ORCID: https://orcid.org/0000-0003-2220-6037

GILBERTO CARBONARI, Dr.| Universidade Estadual de Londrina | Engenharia Civil | Londrina, PR - Brasil | Correspondência para: (Rua Jerusalém, 300, apto 1704, bloco 3 - Londrina PR, CEP: 86050-520) | E-mail: carbonar@uel.br

ORCID: https://orcid.org/0000-0002-8088-3362

GUSTAVO PRONI | Universidade Estadual de Londrina | Engenharia Civil | Londrina, PR - Brasil | Correspondência para: (Avenida Juscelino Kubitschek, 1361, apto 904 Londrina - PR, CEP: 86020-000) | E-mail: gustavoproni@ hotmail.com

ORCID: https://orcid.org/0000-0001-8369-6696

VITÓRIA MARIAGONÇALVES|Univeridade Estadual de Londrina | Engenharia Civil | Londrina, PR - Brasil | Correspondência para: Rua Santo Menegazzo, 197 - Londrina-PR, CEP: 86072-280) | E-maill: vitoriamgonc@gmail.com

\section{COMO CITAR ESTE ARTIGO}

CARBONARI, Gilberto; PRONI, Gustavo; GONÇALVES, Vitória Maria. Aplicação estrutural do bambu - tesouras de duas águas: Análise teórica-experimental. MIX Sustentável, [S.I.], v. 5, n. 1, p. 19-33, mar-jun.

2019. ISSN 24473073. Disponível em: <http://www. nexos.ufsc.br/index.php/mixsustentavel>. Acesso em: dia mês. ano. doi:https://doi.org/10.29183/2447-3073. MIX2019.v5.n1.19-33. 